\title{
Cytomorphological Study of choroid plexus neoplasms and its Correlation with histopathology
}

\author{
Pamu Pramod kumar, Yalavarthi Sushma* and Pagidikalava Aparna \\ Dept. Of Pathology, Mamata Medical College, Khammam, Telangana, India
}

\section{ABSTRACT}

Background: Choroid plexus neoplasms are uncommon and constitute 0.3 to $0.6 \%$ of all brain tumors and 2 to $4 \%$ of brain tumors in children below 15 years. Choroid plexus neoplasms pose considerable treatment challenges. CNS Squash cytology (CSC) helps neurosurgeons immensely in the management of choroid plexus neoplasms. The present study aimed at cytomorphological examination of choroid plexus neoplasms on squash smears and to differentiate them from other papillary neoplasms in that location and to correlate with histopathological details.

Methods: Intraoperative squash smears of twelve cases of SOLs (Space Occupying Lesions) of ventricles and cerebellopontine angle were included in the present study. Cytological diagnoses were correlated with MRI diagnosis and histopathological evaluation.

Result: The study group included 9 (75\%) cases of choroid plexus papilloma (CPP), 03 (25\%) cases of choroid plexus carcinoma (CPC). Age range was 3 months to 58 years (mean=20.5 yrs) and had equal sex distribution. The tumors were distributed as follows: lateral ventricle ( 1 ; $8.33 \%)$, fourth ventricle and fourth ventricle with cerebellopontine angle extension $(10 ; 83.34 \%)$, and third ventricle $(1 ; 8.33 \%)$.

Conclusion: Histopathological examination is gold standard in differentiating choroid plexus neoplasms from other papillary neoplasms like Ependymoma and Metastatic adenocarcinoma.

Keywords: Squash Cytology, Histopathology, Choroid Plexus Neoplasms.

\section{Introduction}

Squash Cytology is a well established and universally accepted technique in diagnosing a wide range of Central Nervous System (CNS) lesions and is being employed for both therapeutic and prognostic reasons. If generous amounts of tissue are provided, a squash preparation is a bridge between a touch imprint preparation and a histologic section. Cytologic features as well as histologic features are often present in this preparation, giving the pathologist the benefits of both worlds. ${ }^{[1]}$ Developing an appropriate list of differential diagnoses is critical to making a correct intraoperative histopathologic diagnosis. This requires awareness of the clinical history, age of the patient, tumor location, and imaging features. Above all, knowledge of the clinicopathologic entities that are frequently seen in specific locations is needed for a clinically correlated pathologic diagnosis. ${ }^{[1,2]}$ This study was conducted with an aim to correlate squash smears of choroid plexus neoplasms with histopathology in differentiating choroid plexus neoplasms from other papillary neoplasms in that location.

\section{Materials and Methods}

All cases of space occupying lesions of ventricles and posterior fossa, which were subjected to intraoperative smear cytology at our hospital, were included in the study after taking institutional ethical committee clearance. The samples were transported from the operation theatre in normal saline with properly filled requisition forms and with complete clinicoradiological details of the patients without any delay. The tissue bits were grossly inspected and squash smears were made from all areas which appeared grossly different. Prepared smears were fixed in $100 \%$ methanol and stained with H\&E stain while the other half was stained with Leishman's stain and Toluidine blue stains. A turnaround time of 30 minutes was taken to render intraoperative diagnosis. Cytological diagnosis was correlated with histopathological diagnosis and observations were recorded. Each case was discussed with the neurosurgeon to find out how useful the intraoperative diagnosis was on diagnostic and therapeutic grounds.

\section{Result}

Total 12 cases of space occupying lesions of ventricles, cerebellopontine angle and posterior fossa were analyzed in the present study. Intraoperative samples from these patients were taken and processed. The age range of patients was 9 months to 58 years. 4 tumors $(33.3 \%)$ were present in infants below 1 year of age. One tumor $(8.33 \%)$ 
was present in child of 10 years age. Rest of the tumors was in adolescents and adults (58.33\%) with an equal male to female (1:1) preponderance.(Table 1) 9 tumors (75\%) were located in $4^{\text {th }}$ ventricle, one tumor each in $3^{\text {rd }}$ ventricle, cerebellopontine angle and posterior fossa(25\%).(Table 1)

In infants and children, all choroid plexus neoplasms ( 5 cases) were located in the Fourth ventricle. In adults, majority was located in the fourth ventricle (4 cases) followed by cerebellopontine angle, third ventricle and posterior fossa (1 case each). (Table 1)

The radiological differential diagnosis given for tumors of $4^{\text {th }}$ ventricle was choroid plexus papilloma, Ependymoma and Medulloblastoma.(Table 1) The tissue bits were grossly inspected and squash smears were made from all areas which appeared grossly different. Majority of $4^{\text {th }}$ ventricular tumors diagnosed cytologically as Choroid plexus papilloma (7cases), one case diagnosed as Ependymoma in 20 years female. Tumor located in posterior fossa in a 45 year female diagnosed cytologically as choroid plexus carcinoma. The cytological impression given for tumors located in $3^{\text {rd }}$ ventricle and cerebellopontine angle was choroid plexus papilloma.(Table 1) Squash smears from choroid plexus papilloma revealed papillaroid structures lined by columnar cells, which are uniform with no evidence of pleomorphism, necrosis, or mitotic figures. Only some cells showed mild atypia. (Fig 1)

On cytologic squash smear preparations, choroid plexus carcinoma showed an irregular papillary architecture and composed of pleomorphic cells with foci of necrosis and calcification. (Fig 2)
Histopathological examination was done and correlated with squash smear cytology. Total cases diagnosed as choroid plexus papilloma in histopathology were 9, choroid plexus carcinoma were 3 cases. Microscopically, the architecture of CPPs looks like normal choroid plexus. The neoplastic villi were lined by simple epithelium, and the core consists of loose connective tissue stroma and a central blood vessel. The epithelial lining cells were uniform in size and shape, and the nuclei were round-to-oval and basally positioned. Apical cytoplasm was abundant, and cilia could be noted for some cells. No cellular atypia or mitotic figures were noted in 9 cases and were labelled as CPP.(Fig 3) In another three cases, tumor revealed sheets of cells with cellular pleomorphism, nuclear atypia, mitotic figures, and necrosis. The epithelial sheath overlying the papillae exhibited areas of stratification, and the stroma was edematous. The epithelial cells were columnar, in some areas, with high nucleus to cytoplasmic ratios and hyperchromatic nuclei. They were labelled as CPC. (Fig 2) Study design included a comparison between results of squash cytology with final histopathological diagnosis. Data analysis was done and calculated sensitivity and specificity of cytology in differentiating benign and malignant lesions.

One case diagnosed as ependymoma on cytology reported as choroid plexus papilloma in histopathology. Two cases of choroid plexus papillomas turned out as choroid plexus carcinoma in histopathology. One case of cytologically diagnosed choroid plexus of carcinoma correlated histopathologically. (Table 2) Sensitivity was 33.33\%, specificity $88.89 \%$, positive predictive value $50 \%$, negative predictive value $80 \%$. (Table 3 )

Table 1: Distribution of choroid plexus neoplasms $(\mathrm{N}=12)$.

\begin{tabular}{|c|c|c|c|c|c|}
\hline SI.NO & Age/Sex & Location & Imageology & Squash & HPE \\
\hline 1 & 9 months/Fch & $4^{\text {th }}$ Ventricle & CPP & CPP & CPP \\
\hline 2 & $18 / F$ & $4^{\text {th }}$ Ventricle & CPP/?Colloid cyst & CPP & CPP \\
\hline 3 & $1 / \mathrm{M}$ & $4^{\text {th }}$ Ventricle & Ependymoma & CPP & CPP \\
\hline 4 & $20 / F$ & $4^{\text {th }}$ Ventricle & Ependymoma/Medulloblastoma & Ependymoma & CPP \\
\hline 5 & 18months/ M ch & $4^{\text {th }}$ Ventricle & ?CPP & $\mathrm{CPP}$ & $\mathrm{CPP}$ \\
\hline 6 & $34 / \mathrm{M}$ & $4^{\text {th }}$ Ventricle & ?Ependymoma & CPP & $\mathrm{CPC}$ \\
\hline 7 & $10 / \mathrm{M}$ & $4^{\text {th }}$ Ventricle & Medulloblastoma & CPP & $\mathrm{CPP}$ \\
\hline 8 & $1 / \mathrm{M} \mathrm{ch}$ & $4^{\text {th }}$ Ventricle & CPP/?PNET & CPP & CPC \\
\hline 9 & $58 / \mathrm{M}$ & $\mathrm{CP}$ angle & Glioma/Shwannoma & CPP & $\mathrm{CPP}$ \\
\hline 10 & $32 / F$ & $3^{\text {rd }}$ Ventricle & Obstructive Hydrocephalus & CPP & $\mathrm{CPP}$ \\
\hline 11 & $45 / F$ & Posterior fosse & $\mathrm{CPP}$ & CPP & $\mathrm{CPC}$ \\
\hline 12 & $17 / F$ & $4^{\text {th }}$ Ventricle & CPP & CPP & CPP \\
\hline
\end{tabular}


Table 2: Discordant cases in Squash cytology.

\begin{tabular}{|c|c|c|c|}
\hline Squash cytology diagnosis & Number(n) & Histopathological diagnosis & Number (n) \\
\hline Choroid plexus papilloma & 10 & $\begin{array}{c}\text { Choroid plexus papilloma } \\
\text { Choroid plexus carcinoma }\end{array}$ & $\begin{array}{c}8 \\
2\end{array}$ \\
\hline Ependymoma & 1 & Choroid plexus papilloma & 1 \\
\hline Choroid plexus carcinoma & 1 & Choroid plexus carcinoma & 1 \\
\hline
\end{tabular}

Table 3: Statistical correlation between squash cytology vs histopathology of choroid plexus neoplasms (Galan \& Gambino Method).

\begin{tabular}{|c|c|}
\hline Sensitivity & $33.33 \%$ \\
\hline Specificity & $88.89 \%$ \\
\hline Positive predictive value & $50 \%$ \\
\hline Negative predictive value & $80 \%$ \\
\hline
\end{tabular}

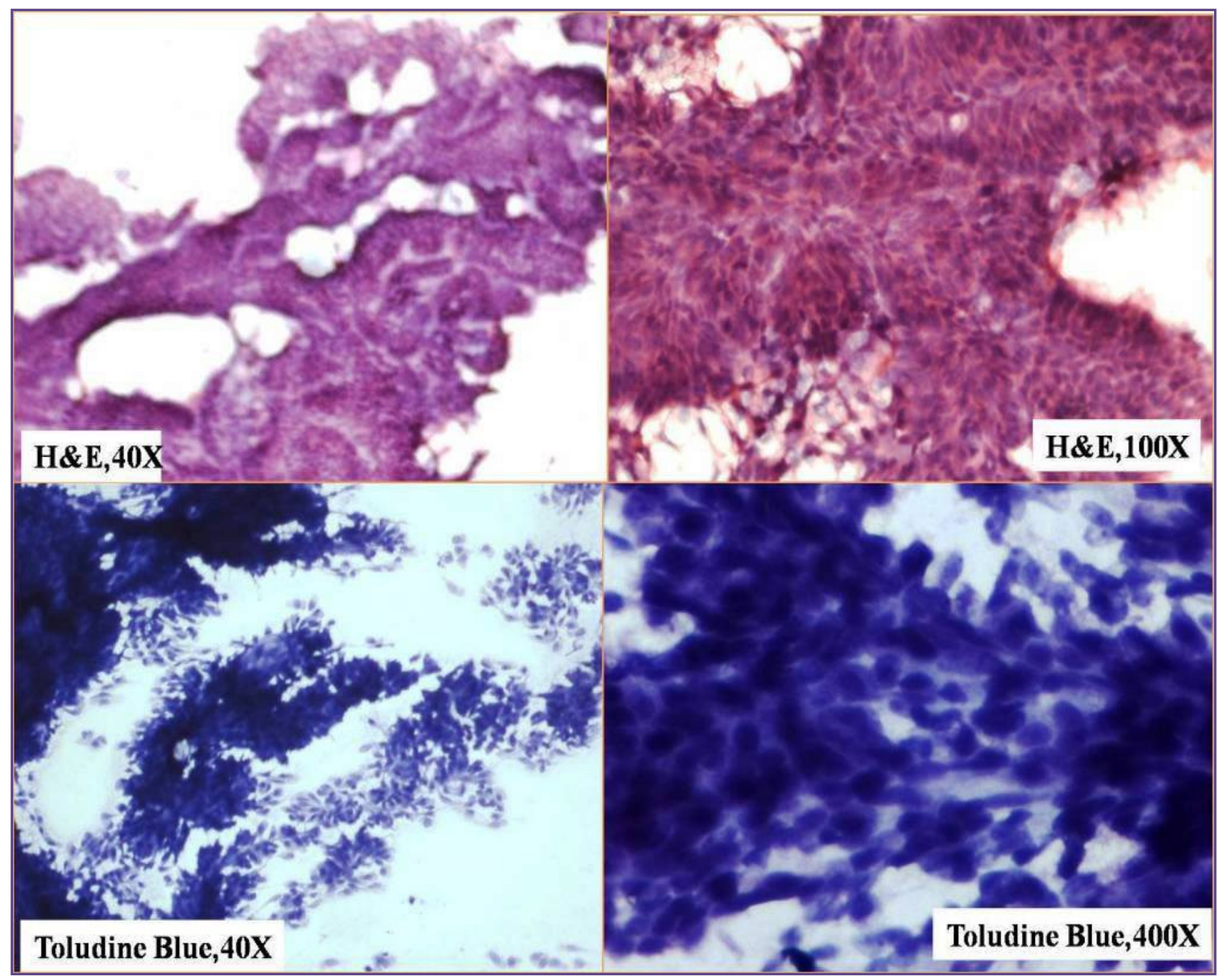

Fig. 1: Squash smears of choroid plexus papilloma showing papillaroid structures lined by uniform columnar cells with no evidence of pleomorphism, necrosis, or mitotic figures. 


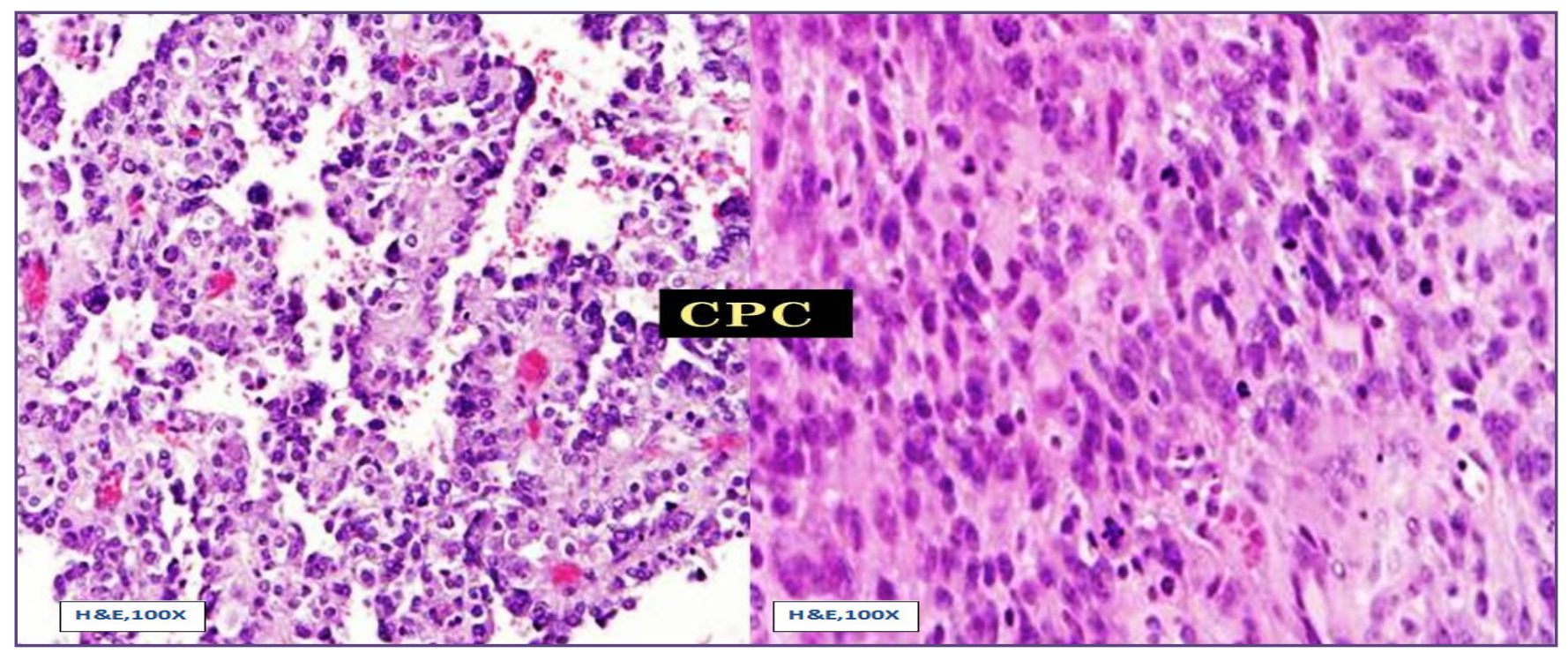

Fig. 2: Cytologic squash smear preparations and histopathological sections of choroid plexus carcinoma showing an irregular papillary architecture and composed of pleomorphic cells with foci of necrosis and mitotic figures (H\&E, 100X \& 400X).

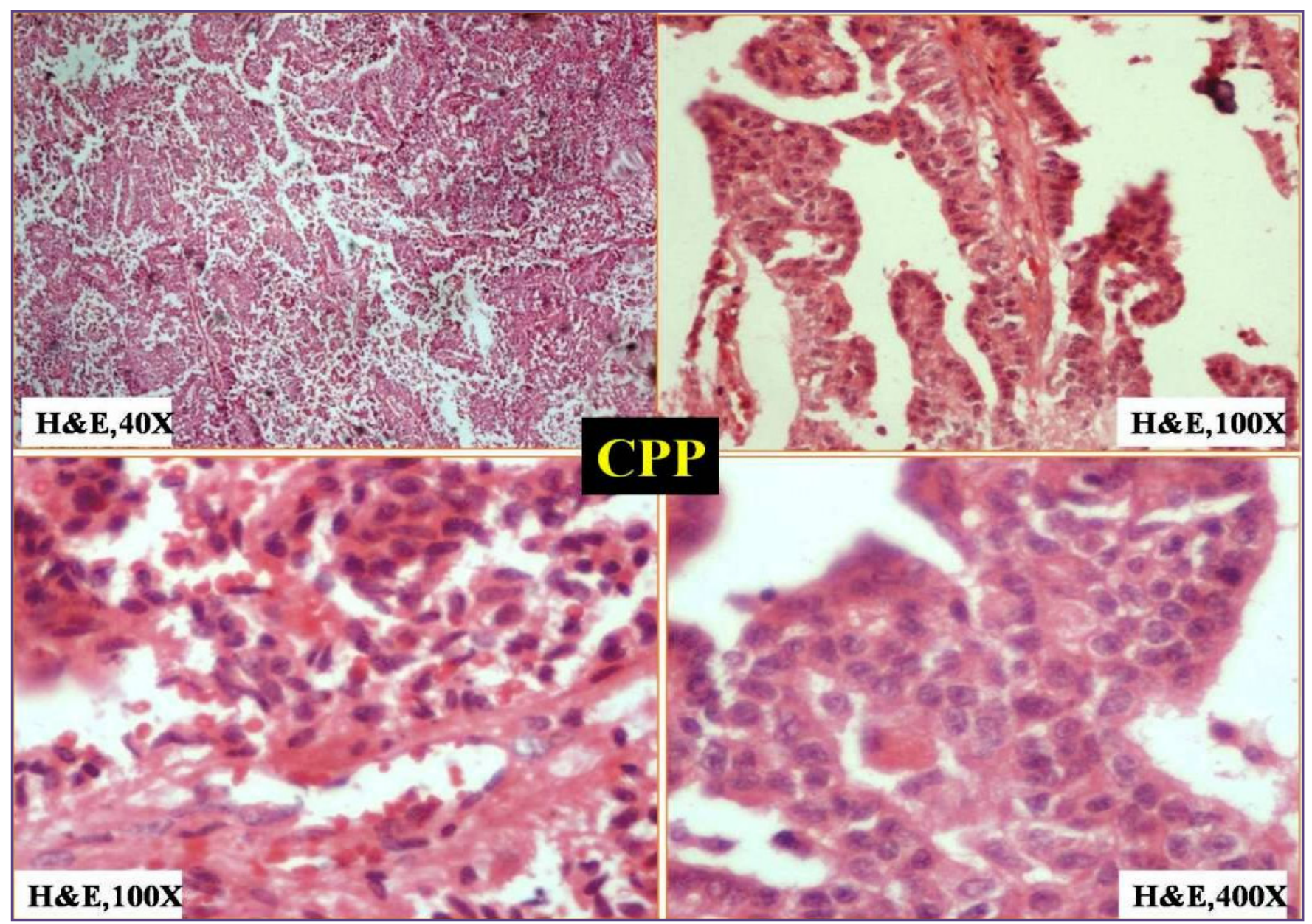

Fig. 3: Histopathological Sections of Choroid Plexus Papilloma showing neoplastic villi lined by single layer of uniform columnar cells and having central fibrovascular core. 


\section{Discussion}

Choroid plexus neoplasms are rare, intraventricular, primary central nervous system (CNS) tumors derived from choroid plexus epithelium, among these choroid plexus papillomas are far more common than carcinomas. They arise most commonly from lateral ventricles in children and fourth ventricle in adults. The third ventricle is the least common intraventricular location for choroid plexus neoplasms, irrespective of patient age. Primary extraventricular papillomas are rare and most often occur at the cerebellopontine angle. Occasionally, involvement of both lateral and multiple ventricles is encountered.

In the present study, most of the choroid plexus neoplasms of childhood and young adults occur in the fourth ventricle. In the adults, they occur in third ventricle, posterior fossa, $\mathrm{CP}$ angle.

Choroid plexus tumors comprise $0.4-0.6 \%$ of all brain tumors. ${ }^{[3]}$ Irrespective of patient age, choroid plexus papillomas outnumber choroid plexus carcinomas by a 5:1 ratio. ${ }^{[2]}$ Although these tumors arise in all age groups, and their peak incidence is within the mid teenage years. ${ }^{[2]}$

Similarly, in the present study also most of the neoplasms are choroid plexus papillomas in the ratio of 3:1.

Choroid plexus neoplasms include choroid plexus papilloma (CPP) (WHO grade I), atypical choroid plexus papilloma (WHO grade II), and choroid plexus carcinoma (CPC) (WHO grade III). ${ }^{[2]}$

Choroid plexus papillomas comprise $1 \%$ of all brain tumors and malignant progression to carcinoma is very uncommon though it has been reported a few times. Distinction between choroid plexus papillomas and choroid plexus carcinomas is made histologically. On microscopic examination an array of branching fibrovascular fronds is seen lined by single layer of uniform cuboidal or columnar cells..$^{[4-7]}$

Choroid plexus papillomas may closely resemble normal choroid plexus or villous hypertrophy on cytology, except choroid plexus papillomas usually have more papillary clusters, sheets, and isolated single cells. The tumor cells tend to be cuboidal to columnar with a moderate amount of cytoplasm and bland nuclei with fine chromatin. Choroid plexus papillomas may also be difficult to distinguish from papillary ependymoma. Papillary ependymomas have multilayered cell clusters with glial processes approaching a central blood vessel. ${ }^{[8]}$

In contrast, the cytologic features of choroid plexus carcinoma include tight three-dimensional clusters and isolated anaplastic cells, variably sized nuclei, a high nuclear-to-cytoplasmic ratio, nuclear indentations and lobulations, single or multiple micronucleoli, and scant, pale, granular cytoplasm. Papillary architecture tends to be minimal or absent, mitotic activity and hypercellularity are obvious, and necrosis is often present. ${ }^{[9]}$ Immunohistochemical analyses for S-100, Cytokeratin, GFAP, and $\mathrm{p} 53$ protein show positivity in carcinoma.

Choroid plexus carcinoma is a highly aggressive malignant tumor seen commonly in the lateral ventricles $(50 \%)$ followed by IV ventricle $(40 \%)$, third ventricle $(5 \%)$, and multiple ventricles (5\%). Almost all choroid plexus carcinomas are seen in children and are extremely rare in adults. ${ }^{[3]}$

The differential diagnosis includes choroid plexus papilloma, villous hypertrophy of choroid plexus, papillary variant of ependymoma or meningioma and metastatic papillary neoplasms Metastasis has been reported in the literature from renal cell carcinoma,esophagus, and carcinoma of thyroid. Differentiation is usually based on associated clinical, cytologic, morphologic, and immunohistochemical features. ${ }^{[10,11]}$

Choroid plexus carcinoma must be distinguished from choroid plexus papilloma and distinction between these entities can sometimes be difficult. The main distinguishing factors are presence of necrosis, mitotic activity, and growth pattern. ${ }^{[3]}$

In the present study, one case of choroid plexus papilloma was diagnosed as ependymoma cytologically. Choroid plexus carcinomas were underdiagnosed as choroid plexus papillomas in Squash smears.

\section{Conclusion}

Cytomorphological and histopathological correlation will aid the neurosurgeons in arriving at the diagnosis of choroid plexus neoplasms and to differentiate them from other papillary neoplasms of that area like Papillary Ependymoma, papillary Meningioma and Metastatic papillary neoplasms.

\section{Reference}

1. Suzanne Z. Powell (2005) Intraoperative Consultation, Cytologic Preparations, and Frozen Section in the Central Nervous System. Archives of Pathology \& Laboratory Medicine 2005;129:1635-1652.

2. Louis DN, Ohgaki H, Wiestler OD, Cavenee WK, eds. Chapter 5: Choroid plexus tumors. WHO Classification of Tumours of the Central Nervous System. Rev 4th ed. Lyon, France: IARC Press;2006:123-9.

3. Kishore S, Negi G, Meena H, Anuradha K, Pathak PV, Bansal K. Choroid plexus carcinoma in an adult. J Neurosci Rural Pract. 2012;3:71-3. 
4. Jeibmann A, Wrede B, Peters O, Wolff JE, Paulus W, Hasselblatt M. Malignant progression in choroid plexus papillomas. J Neurosurg. 2007;107:199-202.

5. Tena-Suck ML, Gomez-Amador JL, Ortiz-Plata A, SalinaLara C, Rembao-Bojorquez D, Vega-Orozco R. Rhabdoid choroid plexus carcinoma: A rare histological type. Arq Neuropsiquiatr. 2007;65:705-9.

6. Berger C, Thiesse P, Lellouch-Tubiana A, Kalifa C, PierreKahn A, Bouffet E. Choroid plexus carcinomas in childhood: Clinical features and prognostic factors. Neurosurgery. 1998;42:470-5.

7. Wang L, Cornford ME. Coincident choroid plexus carcinoma and adrenocortical carcinoma with elevated p53 expression.
A case report of an 18-month-old boy with no family history of cancer. Arch Pathol Lab Med. 2001;126:70-2.

8. Buchino JJ, Mason KG. Choroid plexus papilloma. Report of a case with cytologic differential diagnosis. Acta cytol. 1992;36:95-7.

9. Savage NM, Crosby JH, Reid Nicholson MD. The cytologic findings in choroid plexus carcinoma: Report of a case with differential diagnosis. Diagn cytopathol. 2012;40:1-6.

10. Bucerius J, Meyka S, Michael B, Biersack HJ, Eter N. Papillary thyroid carcinoma with an uncommon spread of hematogenous metastases to the choroid and the skin. J Natl Med Assoc. 2008;100:104-7.

11. Gopal P, Parker JR, Debski R, Parker JC. Choroid plexus carcinoma. Arch Pathol Lab Med. 2008;132:1350-4.

*Corresponding author:

Yalavarthi Sushma, Professor, Dept Of Pathology, Mamata Medical College, Khammam, Telangana, India 507002.

Phone: +91 9848676441

Email: yalavarthisushma@yahoo.co.in

Financial or other Competing Interests: None. 